\title{
Kitosanın Özellikleri, Uygulama Alanları, Bitki Sistemlerine Etkileri
}

\author{
Properties of Chitosan, Application Areas, Effects on Plant Systems
}

\begin{abstract}
Gamze KURTULUŞ ${ }^{1}$ (i) , Filiz VARDAR ${ }^{2}$ (iD)
1,2 Marmara Üniversitesi, Fen Edebiyat Fakültesi, Biyoloji Bölümü, 34722, Göztepe, İstanbul

$\ddot{O} \mathbf{z}$

Tarımda ürün eldesi sırasında meydana gelen ekonomik kayıpları azaltmak için uzun yıllardır kullanılan kimyasal yöntemler, insan sağlığı ve ekolojik dengeyi olumsuz etkilemektedir. Bu nedenle son yıllarda çevreye zararsız iyileştirme yöntemleri ile ilgili araştırmalar artmıştır. Kimyasal ürünlere alternatif olarak tercih edilen doğal iyileştiricilerden birisi de kitosandır. Kitosan, çoğunlukla yengeç, ıstakoz, karides gibi kabuklu su canlılarının iskeletinde yaygın olarak bulunan kitinden deasetilasyon yöntemiyle elde edilmektedir. Kitosan antiviral, antibakteriyel ve antifungal özelliğe sahip olmasının yanında, bitkilerin savunma sistemini de teşvik ederek hastalıkların kontrolü ve yayılmalarının azaltılmasında da etkili bir ajandır. Bunun yanında bulunduğu ortamda (su, toprak vb.) metal iyonlarını şelatlaması ve bitkilerin toksik etkili metallerin alınımını engellemesi nedeniyle tarım alanında iyileştirmede de kullanılmaya başlanmıştır. Yapılan çok sayıdaki çalışmaya rağmen kitosanın bitkilerdeki etki mekanizması tam olarak aydınlatılamamıştır. Kitosanla ilgili detaylı çalışmaların artması, tarıms al alanlarda kitosan kullanımı ile ürünlerden yüksek verim alınabilmesi için yardımcı olacaktır.
\end{abstract}

Anahtar Kelimeler: Kitin; Kitosan; Biyopolimer; Tarım; Bitki

\begin{abstract}
Chemical methods that have been used for many years to reduce the economic losses during agricultural production have an adverse effect on human health and ecological balance. Therefore, in recent years, researches about harmless environmental improvement methods have increased. One of the preferred natural conditioners as an alternative to chemical products is chitosan. Chitosan is obtained from the chitin deacetylation method, which is commonly found in the skeleton of shellfish such as crab, lobster, shrimp. Besides having antiviral, antibacterial and antifungal properties, chitosan is an effective agent in controlling and reducing the spread of diseases by promoting the defense system of plants. In addition to this, it has been started to be used in the agricultural field as it chelates metal ions in its environment (water, soil, etc.) and prevents the ingestion of toxic effective metals by the plants. Despite many studies, the mechanism of action of chitosan in plants has not been fully elucidated. The increase in detailed studies on chitosan will help to obtain high yields of products with the use of chitosan in agricultural fields.
\end{abstract}

Keywords: Chitin; Chitosan; Biopolymer; Agriculture; Plant

\section{GíRiş}

Yeryüzünde selülozdan sonra en sık rastlanan polisakkarit kitindir. Kitinin en önemli türevlerinden biri olan kitosan ise kitinin alkali ortamda kısmen ya da tamamen deasetilasyonu (organik bir bileşikten asetil fonksiyonel grubunun çıkarılması) ile elde edilen polikatyonik özellikte bir biyopolimerdir [1,2]. Kitosanın enzimatik hidrolizinden ise kitosan oligosakkaritleri oluşmaktadır. Mantar, kerevit, karides ve yengeçlerin dış iskeleti gibi kitin içeren birçok doğal kaynaktan bol miktarda elde edilebilen kitosan, organizmalar için toksik özellik içermemesi, biyolojik olarak kolay parçalanması ve biyouyumluk gibi özellikleri bakımından kitin dahil diğer biyopolimerlerden daha avantajlıdır [3,4]. Bu nedenle kitosan başta gıda, medikal, eczacılık, kozmetik, ziraat, atık su arıtması ve tekstil gibi birçok endüstriyel alanda kullanılan doğal, güvenli ve hammaddesi ucuz bir biyopolimerdir [5]. Kitosan antiviral, antibakteriyel ve antifungal özelliğe sahip olmasının yanında, bitkilerin savunma sistemini de teşvik ederek hastalıkların kontrolü ve yayılmalarının azaltılmasında da etkili bir ajandır. Bunun yanında bulunduğu ortamda (su, toprak vb.) metal iyonlarını şelatlaması ve bitkilerde toksik etkili metallerin alınımını engellemesi nedeniyle tarım alanında iyileştirmede de kullanılmaya başlanmıştır $[6,7]$.

1980'li yıllardan itibaren tarımda biyofertilizer, biyopestisit, tohum ve meyveler için kaplama maddesi olarak kitosandan faydalanılmaktadır [4]. Küresel pazarda kitosan üretimi ve kullanımı özellikle Kuzey Amerika, Avrupa ve Asya-Pasifik, Güney Amerika, Orta Doğu ve Afrika'da daha yaygındır. Kitosan kullanımı dünya genelinde özellikle Çin, ABD, Avrupa ve Japonya'da yoğunlaşmıştır. 2015 yılında Çin ve Avrupa, sırasıyla 
$\% 43.32$ ve \%22.22'lik üretim pazar payı ile 5401 megaton ve 2770 megaton üretime ulaşmıştır. ABD ise 2015 y1lında üretim pazar payı \%17.63 olan bir diğer önemli kitosan üretim bölgesidir. Son araştırmalara göre kitosanın dünya pazarının önümüzdeki beş yıl içinde yaklaşık \% 3.3'lük oranında yıllık büyüme oranı beklenmektedir. Yapılan yeni çalışmalara göre 2019 yılında 330 milyon ABD doları olan kitosan pazarlama payının, 2024'te 400 milyon ABD dolarına ulaşması beklenmektedir [8]. Türkiye'de ise kitosanın değerlendirilmesiyle ilişkin bir veri henüz bulunmamaktadır. TÜiK 2018 verilerine göre yaklaşık 4500 ton kerevit, karides, yengeç ve 1stakoz avlanırken bu kabuklu su ürünlerinin \%20'si yenilmekte ve \%80'i atık olmaktadır. Yaklaşık 3500 tonluk su ürünleri atığ uygun bir şekilde değerlendirilerek ortadan kaldırılabilir. $\mathrm{Bu}$ doğrultuda bu atıkların kitin veya kitosan gibi katma değeri yüksek ve sanayinin birçok dalında kullanılabilecek bir ürüne dönüştürülmesi ülke ekonomisine katkı sağlayabilir [9].

Özellikle, antimikrobiyal etkileri sebebiyle çeşitli patojenlere karşı kullanılan kitosan uygulaması bitki hücrelerinde lignin birikimi, kalloz oluşumu, hücre içi iyon miktarı değişimi, sitoplazmada asidikleşme, zar depolarizasyonu, protein fosforilasyonu, kitinaz ve glukanaz aktivasyonu, fitoaleksinlerin biyosentezi, reaktif oksijen türlerinin üretimi, jasmonik asit sentezi ve savunma ile ilgili genlerin ekspresyonu gibi değişikliklere neden olarak bitki savunma sistemini teşvik eder. Kitosanın bitki savunmasını güçlendirmeye yardımcı olması, patojenlere ve çeşitli stres faktörlerine karşı etkili olması ve ürünlerde verimin artırılmasına yardımcı olması gibi özellikleri nedeniyle son yıllarda bu konular üzerinde araştırmalar artmıştır. Yapılan çalışmalar sonucunda, birçok alanda yaygın olarak kullanılan kitosan ve kitooligosakkaritlerin aktivitelerinin polimerizasyon derecesi, deasetilasyon derecesi, $\mathrm{pH}$, sicaklık, konsantrasyon, uygulama yöntemi (direkt toprağa karıştırma, yapraktan uygulama, tek başına veya başka ajanlarla birlikte kullanma), viskozite ve saflık oranı gibi pek çok faktörden etkilendikleri gösterilmiştir $[7,10]$.

\section{KITOSANIN KIMYASAL YAPISI VE ÖZELLIKKLERİ}

Kitin önemli bir polisakkarit olup, temel olarak poli[ $\beta$ - $(1,4)-2$-asetamid-2-deoksi- $\beta$-D-glukopiranoz]

kimyasal yapısına sahiptir ve az miktarda 2-amino-2deoksi- $\beta$-glukopiranoz monomerlerini de içermektedir [11]. Kitosanın temel yapısı ise, poli-[ $\beta-(1,4)-2-$ amino-2-deoksi- $\beta$-D-glukopiranoz] şeklindedir (Şekil 1). Kitin ve kitosan kimyasal yapı açısından selüloza oldukça benzemektedirler. Selülozun ikinci karbon atomunda hidroksil (-OH) grubu bağlı iken, kitinde asetamid (-NHCOCH 3$)$, kitosanda ise amin $\left(-\mathrm{NH}_{2}\right)$ grubu yer almaktadir [12].

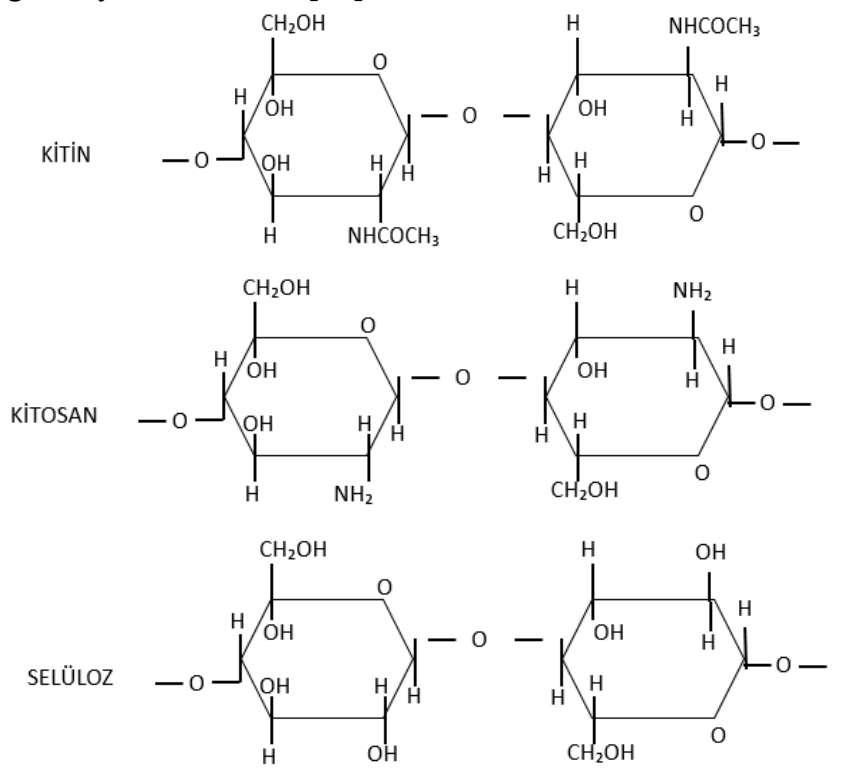

Şekil 1. Kitin, kitosan ve selülozun kimyasal yapıları.

Kitinden kitosan elde edilmesi genel olarak dört aşamadan oluşmaktadır: (1) deproteinizasyon, (2) demineralizasyon, dekolorizasyon (renksizleştirme) ve (4) deasetilizasyon [13]. İlk üç basamakta ham kitin izole edilmekte ve son basamak olan deasetilizasyonda ise kitosan elde edilmektedir. Kitosan eldesi için sıklıkla kullanılan kabuklu deniz hayvanları öncelikle birkaç kez yıkanıp sterilize edilmeli, kurutulmalı ve öğüülerek toz haline getirilmelidir. Kitosan eldesi için sıklıkla kullanılan kabuklu deniz hayvanları \%30-40 oranında protein de bulundurmaktadır. Özellikle biyomedikal ve gida alanındaki kullanımlarda kitosanın içerdiği proteinin alerjik reaksiyonlara sebep olmasından dolayı kitinin yapısındaki proteinlerin kovalent bağları, deproteinizasyon işlemi ile koparılmaktadır. Bu işlem sirasinda en uygun madde olan sodyum hidroksit $(\mathrm{NaOH}) \quad$ kullanılmaktadır. $\mathrm{NaOH}$ kitinin deasetillenmesine ve protein içeriğinin \%1 oranına kadar düşmesine yardımcı olur. Kalan proteinin uzaklaştırılması için pepsin, tripsin gibi proteolitik enzimler de ayrica kullanılmaktadır. Demineralizasyon aşamasında ise yapıda yer alan $\mathrm{CaCO}_{3}$ gibi mineralleri çıkarmak için $\mathrm{HCl}$ gibi asitler kullanılır. Kitin bu aşamalardan sonra astaksantin pigmentinin varlığından dolayı açık pembe renktedir. Renksizleștirme aşamasında aseton, $\mathrm{NaOCl}, \mathrm{KMnO}_{4}$ gibi çeşitli organik çözücüler kullanılır. Bu işlemden sonra gerçekleştirilen deasetilasyon işlemi, kitinin yapısındaki aminoasetil gruplarından asetil grubunun uzaklaştırılması ve geriye yalnızca amin grubu bırakılmasıyla gerçekleştirilir. Deasetilasyon derecesi ise glukozaminin, $\mathrm{N}$-asetil glukozamin ünitelerine oranıdır. Kitinin $\mathrm{NaOH}$ ile deasetillenmesi ve hidrolize edilmesi sonucunda, moleküler ağırlıkta 
kayıplar olur. $\mathrm{Bu}$ işlemler sonucunda elde edilen ürün kitosandır. Elde edilen biyopolimer son olarak \%2'lik asetik asit çözeltisinde çözüldükten sonra filtrasyon ile saflaştırılır, çöktürme ve kurutma aşamalarından sonra depolanır [14].

Kitinin hidrofobik özelliği ve birçok organik çözücüde çözünememesi canlı sistemlerdeki kullanımını sınırlar [11]. Kitosan $\mathrm{pH}$ 6.3'te primer amin grupları taşıması sebebiyle alkali yapıda sayılmaktadır. $\mathrm{Bu}$ nedenle $\mathrm{pH}$ 6.0'dan düşük olan asetik asit, formik asit ve laktik asit gibi seyreltik asitlerde çözünebilmektedir. Kitosan, formik asitin sulu çözeltilerinde kolaylıkla çözündüğü halde en yaygın kullanılan çözücü, pH 4-5 aralığındaki \%1-2'lik asetik asittir [15]. Kitosan amin ve hidroksil grupları içermesi sebebiyle, kitine göre daha kolay çözünen, fiziksel ve kimyasal etkileşimlerde daha aktif bir polimerdir. Düşük pH değerlerinde içerdiği serbest amin grupları sayesinde, kitosan kuarterner amonyum tuzlarına dönüşebilmektedir [16].

Kitosan, düşük pH'larda polikatyonik özelliktedir $(\mathrm{pK}=6,2-6,8)$. Kimyasal yapısındaki $\mathrm{NH}_{2}$ grubu asidik ortamda pozitif yüklü $-\mathrm{NH}_{3}{ }^{+}$şeklinde bulunmakta ve böylece negatif yüklü iyonlar ile etkileşebilmektedir. Örneğin, mekanik olarak parçalanmış kitosan nanofibrilleri bakır $(\mathrm{Cu})$, kurşun $(\mathrm{Pb})$, nikel $(\mathrm{Ni})$, çinko $(\mathrm{Zn})$, krom $(\mathrm{Cr})$, alüminyum (Al) ve kadmiyum (Cd) gibi metal iyonlarını şelatlama maddeleri olarak kullanılmışlardır [17, 18]. Kitosan, bu şelatlama özelliği sayesinde toksik ağır metallerin ayrıştırılmasında kullanılabilmektedir. Bunun yanında abiyotik stres faktörlerinden olan su stresi ve ağır metallerden kadmiyum stresinin iyileştirilmesi için de farklı konsantrasyonlarda kitosanın etkili olduğu belirlenmiştir [19, 20, 21].

Kitosan bitkilerde tohuma, yaprağa, meyveye uygulanarak etki ettiği gibi bitkinin yetiştirildiği ortama, toprağa ve suya uygulandiğında da etki etmektedir. Örneğin; marulda yaprak biyokütle miktarını artırmak [22], Daikon turpunda sürgün ve kök gelişimini artırmak [23], çarkıfelek meyvesinde çiçeklenme süresini hızlandırmak ve çiçek sayısını artırmak [24], Eustoma grandiflorum'un büyümesini ve çiçeklenme zamanını hızlandırmak [25] için de kullanılmıştır. Kitosan ve kitooligosakkaritler metal şelatlama özelliklerine sahip olmalarından dolayı fitoremediasyon (bitkisel arıtma) ve biyofortifikasyon (yenebilir bitkilerin besin değerlerinin artırılması) işlemlerinde de kullanılabilmektedir [6]. Su kültürü ortamına eklenen kitooligosakkaritler fasulye kök uzunluğunda, mineral birikiminde ve sürgün biyokütlesinde değişiklikler meydana getirmiştir [26].

Kitosanın tüm bu farklı kimyasal ve fiziksel özellikleri, aktiviteleri ve etki mekanizmaları ile yakın ilişkilidir. Fiziksel özellik olarak; toz halindeki kitosan oldukça yumuşaktır ve rengi beyaz veya açık sarı tonlarındadır. Kitosan diğer özelliklerinin yanında en çok moleküler ağırlığı ile karakterize edilen bir biyopolimerdir. Elde edildiği kaynak materyaline ve hazırlama metoduna bağlı olarak (deasetilasyon koşulları, sıcaklık, zaman ve $\mathrm{NaOH}$ konsantrasyonu vb.), ticari kitosanın moleküler ağırlığı 10-100.000 $\mathrm{kDa}$ arasında değişir [27]. Kitosanın moleküler ağırlığı yoğunluk, su tutma kapasitesi, biyolojik bozunabilirlik, termal stabilitesi gibi bazı fiziksel, kimyasal ve biyolojik özelliklerini etkilemektedir [28]. Kitosanın saflık derecesi biyolojik özelliklerini etkilerken aynı zamanda çözünürlük ve stabilitesini de önemli derecede etkileyen bir faktördür. Çözünürlükleri de diğer fiziksel özelliklerine, çözücünün türüne, sıcaklık ve pH'ya bağlı olarak etkilenmektedir. Kitosanın kitinden elde edilmesi aşamasında yüksek sıcaklıktan kaçınılmalıdır, çünkü sıcaklık, polimerin fizikokimyasal yapısını bozabilmektedir [29]. Kitosan elde edildikten sonra da oda sıcaklığında uzun süre muhafaza edilmeyip $+4^{\circ} \mathrm{C}$ 'de saklanmalidır. Bunların yanında başlangıçtaki ve saklama koşullarındaki nem seviyesi, kitosanın yapısında bulunan reaktif grupları kolayca kimyasal modifikasyona uğratıp fiziksel özelliklerini değiştirebilmektedir.

\section{KITTOSANIN BITTKIILERDE BIYYOTIK VE ABIYYOTIK STRESE KARŞI KULLANIMI}

Kitosan diğer polimerlerle karşılaştırıldığında biyouyumluluk, biyobozunurluk ve toksik olmayan özellikleri sebebiyle sağlık, gıda, endüstri ve tarım gibi birçok alanda sıklıkla tercih edilmektedir [30]. Kitosanın tarım alanında kullanımı diğer endüstriyel alanlara oranla yaklaşık \%12'dir ve bu oranın hızla arttığ

Son zamanlarda ziraatsal faaliyetlerdeki uygulamaları yaygınlaşan kitosan, antiviral, antibakteriyel ve antifungal özelliklere sahip olduğundan hastalıkları kontrol altına almak veya yayılmalarını azaltmak, besin maddelerini ve mineralleri şelatlamak, patojenlerin yayılmasını önlemek veya bitki doğal savunmalarını geliştirmek için sıklıkla kullanılmaktadır. Biyotik strese karşı bitkiyi koruma amaçlı kullanımı iki biçimde olmaktadır: (1) Ürünü kaplayarak patojenlerden korumak ya da (2) Muhtemel enfeksiyon öncesi bitkilere uygulayarak dayanıklılık mekanizmasını harekete geçirmek [32].

Bitkide hastalıklara karşı direnç artıran çok önemli bir polisakkarit olarak görülen kitosanın domates, şeftali, kivi, armut gibi meyvelerde hasat sonrası patojen sebepli bozulmaları azalttığı gösterilmiştir [33]. Botrytis cinerea ve Rhizopus stolonifer bulaştırılmış çilek meyvelerinin $10 \mu \mathrm{g} / \mathrm{ml}$ ve $15 \mu \mathrm{g} / \mathrm{ml}$ kitosan solüsyonuna daldırılarak kaplanmasından 14 gün sonra depolama sırasında meyvelerde çürümenin önemli derecede azaldığı rapor edilmiştir [34]. Ayrıca antibiyotik içeren yenilebilir kitosan filmlerinin, 
yiyeceklerde bozulmaya yol açabilen birçok bakteriyel ve fungal etmeni engelleyebilir özellikte olduğu belirlenmiştir [35]. Bağlarda meyve tutumundan itibaren 3 kez uygulanan kitosanın, depolanmıs üzümlerde Botrytis sp. enfeksiyonlarını azalttığı ve kaliteyi yükselttiği belirlenmiştir [36]. Üzümlere hasat öncesi 5 gün üst üste püskürtülen $\% 1$ oranındaki kitosanın, hasat sonrası inoküle edilen $B$. cinerea'nın enfeksiyonlarını da önemli derece de azalttığı görülmüştür [37]. Kirazlarda depo çürüklüğüne neden olan Molinilia laxa, B. cinerea, $R$. stolonifer, Alternaria sp. ve Penicillium sp.'nin gelişimini önlemek amaciyla hasattan üç gün önce ve hasat sonrasi uygulanan kitosan, meyveleri $+20 \pm 1^{\circ} \mathrm{C}^{\prime}$ de 10 gün ve $+0.5 \pm 1^{\circ} \mathrm{C}^{\prime}$ de 14 gün boyunca depoda korumuştur [38].

Kitosanın bitkilerde patojenlere dayanıklılık ile ilişkili genleri aktive ettiği düşünülmektedir [39]. Kitosanın oligomerlerinin değişik moleküler ağırlıklara ve asetilasyon derecelerine sahip olmaları, bitkiye uygulandıklarında gerçekleşen fitoaleksinlerin sentez ve birikiminin farklı düzeylerde olmasını etkilemektedir. En yüksek fitoaleksin birikimine 48 saat içinde molekül ağırlı̆ğ $1500 \mathrm{kDa}$ olan ve \%20 asetilasyon derecesindeki kitosanın yol açtığı rapor edilmiştir. Ancak yüksek molekül ağırlığındaki oligomerlerin daha düşük etkili olduğu belirlenmiştir. Bunun yanında düşük yoğunluktaki bakır sülfatla birlikte uygulanmalarının etkilerini artırdığı da saptanmıştır [40]. Buna karşın fasulyelerde ve bezelyelerde Fusarium solani f. sp. phaseoli ile $F$. solani f. sp. pisi'ye karşı ise yüksek molekül ağırlığındaki kitosanın daha etkili olduğu ve bezelyelerde fitoaleksin üretiminin başlatılmasındaki etkisiyle hastalık direncinde merkezi bir rol oynadığı bildirilmektedir [41]. Yer fistığında pas hastalığına ve portakallarda Penicillum digitatum'a karşı kitosanın antifungal özellikteki hidrolazları artırarak dayanıklılık sağlamakta olduğu ortaya çıkarılmıştır [42]. Tütün yapraklarına uygulanan kitosan antioksidan enzim aktivitesinde artışlara neden olmuştur [35]. Bağlara uygulanan kitosan ise depolanmış üzümlerde endokitinaz aktivitesini artırmış, ancak reaktif oksijen türlerinden biri olan hidrojen peroksit içeriğini azaltmıştır [36].

Kitosan, doğal veya değiştirilmiş yapısına, polimerizasyon derecesine, konakçıya, substratların kimyasal ve/veya besin kompozisyonuna ve çevresel koşullara bağlı olarak çeşitli antimikrobiyal aktiviteler sergilemektedir [10]. Yapılan çalışmalara göre, kitosanın moleküler ağırlı̆g arttıkça antimikrobial aktivitesinin de arttığı ve bakterilere oranla mantar ve alglere karşı daha hızlı antimikrobiyal aktivite gösterdiği görülmüştür [43]. Kitosanın fitoaleksinler [44], kalloz [45], lignin [46], patojenle ilişkili proteinler (PR) ve proteinaz inhibitörleri [10] gibi çeşitli antimikrobial bileşiklerin biyosentezini indüklediği de bilinmektedir.

Birçok araştırıcı, kitosan ve kitosan türevlerinin bitkinin; bakterilere [47, 48], mantarlara [49] ve nematodlara $[50,51]$ karşı savunmasını artırmak için kullanılabileceğini rapor etmiştir. Bitkilerde kitosanın antipatojen olarak kullanıldığı ilk çalışmada mantarlardaki farklı hücre duvarı bileşimleri üzerindeki fungisidal etkileri bildirilmiştir [52].

Kitosanın bitkide virüslerin ve viroidlerin sistemik yayılımlarını da inhibe ettiği ve konakçıda enfeksiyona karşı aşırı duyarlı yanıta (hypersensitive response) yol açtığ 1 görülmüştür $[53,54]$. Örneğin, fasulye bitkisinde kitosan, fasulye adi mozaik nekroz virüsüne karşı direnç oluşturmasına yardımcı olur [43]. Araştırıcılar viral enfeksiyonların önlenmesinin kitosanın moleküler ağırlığına göre değişkenlik gösterdiğini belirlemişlerdir [55].

Kitosan geniş bir antimikrobial aktivite spektrumuna sahip olmasına rağmen, farklı mantarlara, Gram pozitif ve Gram negatif bakterilere karşı farklı inhibisyon verimliliği sergilemektedir [56]. Mevcut kanitlara dayanarak, bakteriler genel olarak mantarlara göre kitosanın antimikrobiyal etkisine karşı daha az duyarlıdır.

Kitosanın çok çeşitli bakterilerin büyümesini engelleyici özelliği vardır [57]. Türlere bağlı olarak kitosanın büyüme önleyici konsantrasyonları değişiklik göstermektedir. Antibakteriyel aktivite, farklı hücre yüzeyi özelliklerinden dolayı Gram pozitif ve Gram negatif bakteriler arasında değişen karmaşık bir süreçtir. Birçok çalışmada, kitosanın Gram negatif bakterilere Gram pozitif bakterilere oranla daha kuvvetli antibakteriyel aktivite gösterdiği belirlenmiştir $[13,58]$.

Özellikle asidik pH'da N, N, N-trimetilkitosan, Npropil-N, N-dimetilkitosan ve N-furfuril-N, Ndimetilkitosan gibi kitosanın kuaterner amonyum tuzlarının Escherichia coli'nin büyümesini ve gelişimini inhibe ettiği görülmüştür [59]. Benzer şekilde, kitin ve kitosanın birkaç türevinin, E.coli, Staphylococcus aureus ve bazı Bacillus türlerinin gelişimlerini engellediği gösterilmiş̧ir [60].

Kitosanın çoğu mantar ve oomycetes türüne karşı antifungal aktivite gösterdiği saptanmıştır [44, 57]. Kitosanın antifungal aktivitesi düşük $\mathrm{pH}$ değerlerinde daha fazladır [61]. Kitosan antifungal etkisini sporülasyonu ve spor çimlenmesini bastırarak gösterir [62]. Örneğin; kitosan armutta Alternaria kikuchiana ve Physalospora piricola'nın çimlenmesini ve büyümesini tamamen engeller [63]. Benzer şekilde pirinçte ise bulaşıcı bir patojen olan Rhizoctonia solani'ye karşı etkin antifungal aktivite gösterir [17]. 
Misır örtü hastalığına neden olan dimorfik mantar Ustilago maydis'in hücre gelişimi kitosan ve glikol kitosan tarafından inhibe edilmiştir [64]. Bunun yanında kitosan uygulaması, patates ve domatesin mantar patojeni olan Fusarium eumartii sporlarında hücre ölümüne yol açmıştır [65]. Kitosan uygulamasının, Penicillium spp. kaynaklı küf hastalıklarından limon (Citrus limon) meyvesini koruduğu da belirlenmiştir [7].

Bitkilerde biyotik streslere karşı kullanılan kitosan, bunun yanında bitki büyüme düzenleyicisi ve abiyotik streslere karşı bitkiyi korumak amaciyla da kullanılmaktadır. Bitki hücre veya doku kültürlerinde hızlı bir şekilde üretimin sağlanmasında, verimin artırılmasında ve sekonder metabolitlerin üretilmesinde abiyotik elisitör (uyarıcı) olarak kullanılmaktadır [66]. Örneğin, Linum usitatissimum L.(keten) hücre kültürlerinde kullanılan kitosan $(10 \mathrm{mg} / \mathrm{L})$ farmakolojik olarak önemli bir polifenol olan lignan biyosentezini düzenleyerek üretimini artırmıştır [67]. Yapılan bir diğer çalışmaya göre ise Solanum tuberosum L. (patates) bitkisinde kitosanın yapraktan uygulanmasının büyümeye ve kuraklık stresine karşı olan etkileri analiz edilmiştir. Elde edilen sonuçlara göre, sürgün yüksekliğinde ve nodların sayısında gelişme, bunun yanında klorofil, karetoidler, prolin ve total şeker miktarlarında önemli ölçüde artış gözlenmiştir. Ayrıca kitosan, kuraklık stresine karşı antioksidan ve savunma enzimlerini indükleyerek katalaz, peroksidaz, superoksit dismutaz enzimlerinde artışı sağlamıştır [68]. Triticum aestivum L. (buğday) ve Zea maize L. (mısır) bitkilerinde tuzluluk stresine karşı, tohumların 3 saat kitosan çözeltisi ile muamele edildikten sonra yetiştirilmeleri, antioksidan enzim aktivitesini ve prolin içeriğini artırarak MDA (Malondialdehit) birikimini azaltmıştır. Sonuç olarak tuzluluk stresi altındaki bitkilerin büyüme performanslarını artırarak strese karşı iyileştirici etki göstermiştir [69].

\subsection{Kitosanın Tohum Kaplama Maddesi Olarak Uygulanması}

Tohumların kitosan ile kaplanması sırasında dikkat edilmesi gereken birçok faktör vardır, ancak kaplama solüsyonlarının konsantrasyonları ile kaplama sirasındaki zaman ve sicaklık en önemlileri arasındadır [70]. Buğday tohumlarında yapılan çalışmaya göre, kitosan ile kaplanan tohumlarda bazı patojenlerin oluşturduğu hastalıklara karşı direncin arttığı ve tohumların kalitesinde ve/veya çimlenme yeteneklerinde gelişme olduğu bildirilmiştir [71]. Kitosan ile nemlendirilmiş yer fistığı tohumlarında ise çimlenme oranında, ATP sentezinde, lipaz aktivitesinde, giberellik asit ve indol asetik asit seviyelerinde artış olduğu gösterilmiştir [72]. Kitosan ile kaplanmış pirinç tohumlarıyla yapılmış olan çalışmada kitosan etkisi ile çimlenmelerinde ve stres koşullarına karşı tolerans geliştirmelerinde artış olduğu gösterilmiştir [73]. Havuçta ise tohum kaplamasının Sclerotinia sclerotiorum'un sebep olduğu beyaz çürüklük hastalığının gelişimini engellemeye yardımcı olduğu rapor edilmiştir [74]. Kitosan solüsyonları ile kaplanan mısır tohumlarıyla yapılan çalışmada, kitosanın mısır tohumlarında çimlenme hızını, sürgün ve kök gelişimini artırmasının yanında membran bütünlüğünü ve antioksidan enzim aktivitelerini de artırarak soğuğa tolerans mekanizmasını hızlandırdığı ortaya koyulmuştur [75].

\subsection{Kitosanın Yaprak İyileştirme Ajanı Olarak Uygulanması}

Kitosanın iyileştirme ajanı olarak yapraklara uygulanmasının bitkisel sistemlerde olumlu sonuçlara yol açtığı birçok çalışma ile gösterilmiştir. Örneğin, pentamer kitosanın soya fasülyesi ve mısır yapraklarına uygulanmasından bir gün sonra net fotosentez oranında değişiklikler saptanmıştır [76]. Kitosanın fasulye bitkisi yapraklarına sprey olarak uygulanması ile transpirasyonun azaldığı belirlenmiştir [77]. Bu durumun kitosan uygulaması sonucunda yapraklardaki absisik asit (ABA) içeriğindeki artış ile ilişkili olduğu ortaya konulmuştur. ABA içeriğinin artması sonucu stomalarda kapanma meydana geldiği ve su buharı giriş çıkışının engellendiği, dolayısıyla transpirasyon oranında bir azalma olduğu ortaya çıkarılmıştır.

Kitosan ayrıca virüsleri, bakterileri, mantarları ve zararlıları içeren birçok hastalığın büyümesini, yayılımını ve gelişimini kontrol etmek amacıyla da yaygın olarak yapraktan uygulama şeklinde kullanılmaktadır [78]. Örneğin, arpa yapraklarına sprey olarak uygulanan kitosan ile patojen Blumeria graminis $f$. sp. hordei tarafindan sistemik olarak meydana gelen enfeksiyon indirgenmiştir [53]. Kitosanın yaprağa uygulanmasının, fasulyede su stresi belirtilerini azaltmada, büyüme ve verim oranını artırmada olumlu etkileri olduğundan umut verici bir tarımsal strateji olabileceği öne sürülmektedir [19].

\subsection{Kitosanın Toprak İyileştirici Ajan Olarak Uygulanması}

Kitosan toprağa uygulandığında topraktaki Bacillus, Pseudomonas, Actinomycetes, Mycorrhiza ve Rhizobacteria gibi faydalı mikroorganizmaların aktivitesini harekete geçirerek, rizosferdeki zararlı bitki patojenlerine karşı mikrobiyal dengeyi değiştirmektedir. Kitosan ayrıca toprak kaynaklı patojenlere karşı bitkide savunma yanıtlarını artırmaktadır [79].

Toprak iyileştiricisi olarak kullanılan kitosanın birçok bitki türünde Fusarium türleri tarafindan oluşturulan solgunlukları kontrol altına aldığı gösterilmiştir [78]. Tarlada yetiştirilen mısır ve yer fistığındaki Aspergillus flavus da toprağa uygulanan kitosan ile tamamen inhibe edilmiştir [34]. Kitosanın toprağa uygulanması bitkinin patojenlere tolerans geliştirmesinde olumlu etkilere sebep olurken, 
vejetatif büyümeyi de olumlu etkilediğine dair sonuçlar elde edilmiştir. Araştırıcılar Eustoma grandiflorum'da bitki büyümesi ve çiçek kalitesine kitosan etkilerini araştırmak için toprağa kitosan uygulamışlardır. Elde edilen sonuçlara göre, kitosan uygulaması çiçeklenmeyi hızlandırmış, çiçek sayısı, yaprak uzunluğu, yaprak genişliği, sürgün boyunda da artışa sebep olmuştur [25]. Kitosanın toprağa ilavesi, Capsicum annuum'da gövde uzunluğu, kanopi çap1 (bitkinin üzerine tam tepeden 1 şı vurduğunda bitkinin gölgesinin oluşturduğu alanın birbirine en uzak olan uçları arasındaki uzaklık) ve yaprak alanında artışa sebep olmuştur [80].

\section{BİTKİ HASTALIKLARININ AZALTILMASINDA KITOSANIN ETKI MEKANIZMALARI VE BİTKILLEIIN VERDİĞİ FIZYOLOJIK YANITLAR}

Kitosanın, konsantrasyon, bitkinin türü ve gelişim aşamasına bağlı olarak, sayısız biyokimyasal ve fizyolojik tepkiyi indükleyen doğal bir biyopolimer olduğu bilinmektedir. Bunun yanında hastalıkları kontrol altına almak veya yayılmalarını azaltmak, besin maddelerini ve zararlı iyonları şelatlamak, patojenlerin farklı dokulara erişmesini önlemek veya bitki doğal savunmalarını geliştirmek için sıklıkla tarımda kullanılmaktadır. Bitki savunmasını arttırmak için kullanıldığında, kitosan hem monokotillerde hem dikotillerde konakçı savunma tepkilerini uyandırır. Temelde bu yanıtlar; ligninleşme [46], iyon değişimi, sitoplazmik asidifikasyon, zar depolarizasyonu, protein fosforilasyonu [81], fitoaleksin biyosentezi [45], reaktif oksijen türlerinin üretilmesi [82], jasmonik asidin biyosentezi [83], özgün erken yanıt veren savunma ile ilişkili genlerin ekspresyonunu [84] içerir.

Kitosanın bitki hastalıklarını azaltmasındaki etki mekanizmasının basamakları tam olarak anlaşılamamış olmasına rağmen, doğrudan toksisite veya patojenlerin besin maddeleri ve minerallerin şelatlanması yoluyla olabileceğini gösteren kanıtlar vardır. Bunun yanında kitosanın bitki dokularına uygulanması, patojenlerin penetrasyon bölgelerinde fiziksel bariyerler oluşturmasına sebep olarak diğer sağlıklı bitkisel dokulara yayılmasını önleyebilmektedir [10].

\subsection{Kitosan ile Besinlerin ve Minerallerin Şelatlanması}

Kitosan bitki hastalıklarını kontrol altına almak ve yayılmalarını engellemek, patojenlerin erişmesini önlemek ve bitki savunmasını geliştirmek dışında besin ve mineralleri şelatlamak (metalleri bağlama) amacıyla da kulanılmaktadır. Daha çok tatlı ve tuzlu su arıtma sürecinde metal iyonlarının, pestisitlerin, fenollerin tutulmasında kullanılan kitosan $\mathrm{Fe}, \mathrm{Cu}$ gibi besin maddelerini ve mineralleri şelatlayarak patojenlerin bunlara erişimini engelleyebilir ve patojen kaynaklı bitki hastalıklarını önleyebilir [10]. Aynı zamanda bu polisakkaritlerin konakçı dokularda zarara yol açan mitotoksinlere bağlanarak zararı azalttıkları bildirilmiştir [85]. İçecek endüstrisinde kullanılan kitosanın şelatlama özelliği ise antimikrobiyal etkisi ile mantar sebepli bozulmayı azaltır. Yapılan bir çalışmaya göre kitosan ile şelatlanmış bakır, bitkinin fazla miktarda bakır almasını ve toprak kirlenmesini önleyerek bitki hastalıklarının tedavisinde başarılı bir şekilde kullanılmıştır [86].

Kitosanın diğer doğal polimerler ile karşılaştırıldığında daha iyi bir şelatlayıcı olduğu belirtilmiştir [87]. Bu sebeple farklı endüstriyel alanlarda metal iyonlarını uzaklaştırmada ve/veya geri kazanmada yaygın olarak kullanılmaktadır. Yüksek deasitilasyon derecesine sahip kitosan türevlerinin $\mathrm{Cu}^{+2}$ için yüksek şelatlama kapasitesine sahip olduğu gösterilmiştir. Buna ek olarak suda çözünebilir kitosan, asitte çözünebilir kitosandan daha yüksek şelatlama kapasitesi göstermiştir. Araştırıcılar bunun sakkaritlerden ekstra fonksiyonel grubun (örn; amino grup) eklenmesiyle ilgili olabileceğini belirtmişlerdir [88]. Fe ve $\mathrm{Zn}$, dünya nüfusunun \%30'undan fazlasını etkileyen, beslenmeyle ilişkili en önemli mineral elementlerden ikisidir ve dolayısıyla bu iki elementin birikimi canlılar için önemlidir [89]. Kitosan ve türevlerinin, $\mathrm{Cu}^{+2}$ 'den sonra en çok $\mathrm{Fe}^{+2}$ 'i şelatladığ ve bunun yanında $\mathrm{Zn}^{+2}$ için şelatlama kapasitesinin daha zor olduğu anlaşılmıştır [90]. Pozitif yüklü kitosan moleküllerinin negatif yüke sahip hücre membranına bağlanarak yapısını bozduğu ve hücrenin içeriğinin dişarıya sızmasına neden olarak antimikrobiyal aktivite sergilediği belirtilmiştir. Ayrica hem temel besin elementleri ile hem de iz elementlerle şelat oluşturup bunların hücre içine taşınmasını engelleyerek mikrobiyal gelişimi önlediği bildirilmiştir [91, 92].

\subsection{Kitosan ve Hücre İçi Sinyal İletimi}

Bitkilerde kitosan tedavisinin abiyotik ve biyotik streslere karşı savunma yanıtlarını artırarak sinyal yollarındaki birkaç geni düzenlediği belirtilmiştir. Örneğin, kitosan uygulaması bitkilerde birkaç geni aktive ederek proteinlerin ve fenolik bileşiklerin üretimini artırmış ve patojenlere karşı toleransı geliştirmiştir [93]. Ayrıca süs bitkilerinin çiçeklenme yeteneklerini artırmada gen yolu düzenlemesinde önemli rol oynadığı gösterilmiştir [94]. Buna ek olarak kitosanın PR (Pathogenesis Related) genlerini indüklediği belirtilmiştir [95].

Kitosan molekünün belirli hücre reseptörleri tarafindan tanınmasından sonra, fizyolojik tepkilerin uyarılması için ikincil habercilerin (sekonder 
metabolitler) sinyal iletilmesinde rol oynaması gerekmektedir. Kitosan aracılı sinyalizasyon yolunda hidrojen peroksit $\left(\mathrm{H}_{2} \mathrm{O}_{2}\right)$ gibi reaktif oksijen türleri (ROT), $\mathrm{Ca}^{+2}$, nitrik oksit (NO) ve fitohormonlar gibi moleküller rol almaktadır [96,97].

Bitki dokularında patojen kaynaklı enfeksiyona karşı oluşan aşırı duyarlı yanıt sırasında savunma amacıyla ROT üretilmektedir. Yapılan bir çalışmaya göre, bitkide patojen saldırısı boyunca bir bitki hormonu olan salisilik asit (SA) sentezlenmekte ve sistemik kazanılmış direnç (SAR) gerçekleştirmek için sinyal oluşumuna katılarak $\mathrm{H}_{2} \mathrm{O}_{2}{ }^{\prime} \mathrm{i}$ parçalayan katalaz enzimini bloke etmekte, böylece $\mathrm{H}_{2} \mathrm{O}_{2}$ 'in üretiminin devamını sağlamaktadır [98]. SA ve jasmonik asit (JA) bitki savunmasında gerekli sinyal iletiminde iki farklı yolakta rol oynayan bitki hormonlarıdır [99, 100]. SA, SAR'e aracılık ederken JA uyarılmış sistemik dirence (ISR) aracılık eder. SA ve JA sinyal yolakları birbirlerini sinerjik ve antagonistik etkileşim ağıyla etkilemektedirler [101, 102]. Kitosan oligosakkariti uygulaması sonucu domates, pirinç ve kolza tohumunda JA sinyal yolu aktivitesi ile JA üretimi indüklenmiş ve bitki bağışıklığı aktive edilmiştir [103, 104]. Benzer olarak, kitosan oligosakkaritinin SA sinyal yolunun aktivasyonu ile tütün mozaik virüsüne (TMV) karşı direnç oluşturduğu bildirilmiştir [105]. Tütün yapraklarında yapılan bir diğer çalışmada ise kitosan oligosakkaritlerinin sirasıyla kloroplast, nukleus, sitosol ve hücre membranında NO oluşumunu indükleyerek bazı savunma ile ilgili enzimlerin aktivitelerini düzenleyebildiği gösterilmiştir [106]. Kitosan uygulanmış farklı bitki ve bitki hücre kültürlerinde $\mathrm{H}_{2} \mathrm{O}_{2}$ birikimi ile oksidatif patlama gözlenmiştir [107, 108]. Böylece, bir hücre içi sinyal olan $\mathrm{H}_{2} \mathrm{O}_{2}$ birçok bitki türünde, bitki savunma enzimlerinin indüklenmesine, polifenolikler, lignin, flavonoidler ve fitoaleksinler gibi sekonder metabolitlerin sentezine yol açmaktadır [7]. Bu türlerden bazıları; ayçiçeği (Helianthus anuus), papaya (Carica papaya), çin ağacı meyvesi (Litchi chinensis), üzüm (Vitis vinifera), soya fasulyesi (Glycine max), domates (Solanum lycopersicum), kayıs1 (Prunus armenica)'dır [63, 96, 109, 110]. Ca ${ }^{+2}$ molekülleri ise hem monokotillerde hem dikotillerde kitosana yanıt olarak kalloz oluşumu aktivitesini düzenlemektedir [76].

\section{SONUCCLAR VE TARTIŞMA}

Modern tarımın en büyük hedefi, dünya nüfusundaki artışa bağlı olarak çevresel etkileri göz önünde bulundurarak kaliteli ve yeterli miktarda gıdayı üretmektir [111]. Tarımsal üretimde birçok zararlı etmenler ve hastallklar sonucu bitki verimi ciddi derecede etkilenmektedir. Uzun yıllar boyunca, bu problemlerle yüzleşmek ve verimi artırmak için kimyasal gübre ve pestisitler kullanılmıştır [7]. Bu ürünlerin kullanımı toprakta artık madde birikimine, dirençli zararlıların gelişmesine, çevre kirlenmesine ve insan sağlığını tehdit edici sorunlara sebep olmuştur. $\mathrm{Bu}$ nedenle araştırmacılar son yıllarda, tarımsal verimliliği artırmak ve zararlı unsurları azaltmak doğrultusunda zararsız ve alternatif yöntemlere yönelmişlerdir. Kitosan ve türevlerinin kullanılması bu alternatif yöntemlerden birisidir. Elde edilmesi ve uygulanması maliyetli olmayan bir biyopolimer olan kitosan, endüstriyel alanda oldukça sık kullanılırken son yıllarda tarımsal uygulamaları oldukça yaygınlaşmıştır. Kitosan biyoçözünürlük ve biyouyumluluk gibi birçok olumlu biyolojik özelliğe sahiptir. En büyük avantajı yenilenebilir bir kaynak ve doğa dostu olmasıdır. Kitosanın etkisi kimyasal yapısına, moleküler ağırlığına, konsantrasyonuna, bitkinin türüne ve uygulama şartlarına bağlı olarak değişirken, bitkide strese karşı dayanıklılık ve artan verim gibi sayısız biyolojik tepkiyi de aktive eder. Ancak yapılan çok sayıdaki çalışmaya rağmen kitosanın etki mekanizması tam anlamıla aydınlatılabilmiş değildir. Daha detaylı moleküler çalışmalar ile kitosanın bitki sistemleri üzerindeki etki mekanizmaları aydınlatılabilir ve böylece bitki hastalıklarının kontrolünde daha iyi bir kullanım sağlanabilir. Kitosanla ilgili biyoteknolojik çalışmaların gittikçe artması ve birçok alanda kimyasal, fiziksel özellikleri gereği kolayca kullanılabilmesi, geleceğe umut verici bir uygulama alanı sunmaktadır.

\section{KAYNAKLAR}

[1]Kumar, M. N. R. (2000). A review of chitin and chitosan applications. Reactive and functional polymers, 46(1), 1-27.

[2]Pandey, P., Verma, M. K., \& De, N. (2018). De N. Chitosan in agricultural context-a review. Bulletin of Environment, Pharmacology and Life Sciences, 7(4), 87-96.

[3]Dutta, P. K., Ravikumar, M. N. V., \& Dutta, J. (2002). Chitin and chitosan for versatile applications. Journal of Macromolecular Science, Part C: Polymer Reviews, 42(3), 307-354.

[4]Malerba, M., \& Cerana, R. (2019). Recent applications of chitin-and chitosan-based polymers in plants. Polymers, 11(5), 839.

[5]Demir, A., \& Seventekin, N. (2009). Kitin, kitosan ve genel kullanım alanları. Tekstil Teknolojileri Elektronik Dergisi, 3(2), 92-103.

[6]Vasconcelos, M. W. (2014). Chitosan and chitooligosaccharide utilization in phytoremediation and biofortification programs: current knowledge and future perspectives. Frontiers in plant science, 5

[7]Malerba, M., \& Cerana, R. (2016). Chitosan effects on plant systems. International journal of molecular sciences, 17(7), 996.

[8]Chitosan Market Share, Size 2020: Company Profiles, Emerging Technologies, Trends, Industry Growth, Segments, Landscape and Demand by 
Forecast to 2024 (2019, Aralı). Market Watch. Erişim adresi:

https://www.marketwatch.com/press-release/chitosanmarket-share-size-2020-company-profiles-emergingtechnologies-trends-industry-growth-segmentslandscape-and-demand-by-forecast-to-2024-2019-1202

[9]Su Ürünleri İstatistikleri (2018). Türkiye İstatistik Кигити. Erişim adresi:

http://www.tuik.gov.tr/PreTablo.do?alt_id=1005

[10]El Hadrami, A., Adam, L. R., El Hadrami, I., \& Daayf, F. (2010). Chitosan in plant protection. Marine drugs, 8(4), 968-987.

[11]Park, B. K., \& Kim, M. M. (2010). Applications of chitin and its derivatives in biological medicine. International journal of molecular sciences, 11(12), 5152-5164.

[12]Koç, B. E., \& Özkan, M. (2011). Gıda endüstrisinde kitosanın kullanımı. Glda Dergisi, 36(3).

[13]No, H. K., Park, N. Y., Lee, S. H., \& Meyers, S. P. (2002). Antibacterial activity of chitosans and chitosan oligomers with different molecular weights. International journal of food microbiology, 74(1-2), 65-72.

[14]Szymańska, E., \& Winnicka, K. (2015). Stability of chitosan - a challenge for pharmaceutical and biomedical applications. Marine drugs, 13(4), 18191846.

[15]Yi, H., Wu, L. Q., Bentley, W. E., Ghodssi, R., Rubloff, G. W., Culver, J. N., \& Payne, G. F. (2005). Biofabrication

chitosan. Biomacromolecules, 6(6), 2881-2894.

[16]Akbulut, Y., \& Bulut, M. O. (2015). Tekstilde Kullanılan Bazı Biyopolimerlerin Tarıma Uygulanabilirliği. SDÜ Yekarum e-Dergi, 3(1).

[17]Liu, H., Tian, W., Li, B., Wu, G., Ibrahim, M., Tao, Z., ... \& Sun, G. (2012). Antifungal effect and mechanism of chitosan against the rice sheath blight pathogen, Rhizoctonia solani. Biotechnology letters, 34(12), 2291-2298.

[18]Liu, D., Li, Z., Zhu, Y., Li, Z., \& Kumar, R. (2014). Recycled chitosan nanofibril as an effective $\mathrm{Cu}$ (II), $\mathrm{Pb}$ (II) and $\mathrm{Cd}$ (II) ionic chelating agent: adsorption and desorption performance. Carbohydrate polymers, 111, 469-476.

[19]Abu-Muriefah SS (2013) Effect of chitosan on common bean (Phaseolus vulgaris L.) plants grown under water stress conditions. Int Res J Agri Sci Soil Sci 3: 192- 199.

[20]Zong H, Liu S, Xing R, Chen X, Li P (2017) Protective effect of chitosan on photosynthesis and antioxidative defense system in edible rape (Brassica rapa L.) in the presence of cadmium. Ecotox. Environ Safe 138: 271-278.

[21]Kurtuluş, G. (2019) Buğday (Triticum aestivum L.)'da Alüminyum Toksisitesine Karşı Kitosan Uygulamasının Etkileri. (Yayımlanmamış Yüksek
Lisans Tezi). Marmara Üniversitesi/Fen Bilimleri Enstitüsü, İstanbul

[22]Benavides-Mendoza, A., Alonso-Velasco, R., Romero-García, J., Ledesma-Pérez, A. S., \& RaygozaCastro, J. M. (2001). LA APLICACION FOLIAR DE QUITOSAN EN ACIDO ACETICO AUMENTA LA BIOMASA DE LA LECHUGA. $X X X \quad V B B B O N Y$, 190.

[23]Tsugita, T. (1993). The application of chitin/chitosan for agriculture. In Proc. of the Special Sess. 7th Symposium on Chitin and Chitosan, 1993 (pp. 21-22). Jap. Soc. for Chitin and Chitosan.

[24]Utsunomiya, N., Kinai, H., Matsui, Y., \& Takebayashi, T. (1998). The effects of chitosan oligosaccharides soil conditioner and nitrogen fertilizer on the flowering and fruit growth of purple passionfruit (Passiflora edulis Sims var. edulis). Journal of the Japanese Society for Horticultural Science, 67(4), 567-571.

[25]Ohta, K., Taniguchi, A., Konishi, N., \& Hosoki, T. (1999). Chitosan treatment affects plant growth and flower quality in Eustoma grandiflorum. HortScience, 34(2), 233-234.

[26]Chatelain, P. G., Pintado, M. E., and Vasconcelos, M. W. (2014). Evaluation of chitooligosaccharide application on mineral accumulation and plant growth in Phaseolus vulgaris. Plant Sci. 215-216, 134-140. doi: 10.1016/j.plantsci.2013.11.009

[27]Tsaih, M. L., \& Chen, R. H. (2003). The effect of reaction time and temperature during heterogenous alkali deacetylation on degree of deacetylation and molecular weight of resulting chitosan. Journal of applied polymer science, 88(13), 2917-2923.

[28]Dash, M., Chiellini, F., Ottenbrite, R. M., \& Chiellini, E. (2011). Chitosan-A versatile semisynthetic polymer in biomedical applications. Progress in polymer science, 36(8), 9811014.

[29]Majekodunmi, S. O. (2016). Current development of extraction, characterization and evaluation of properties of chitosan and its use in medicine and pharmaceutical industry. American Journal of Polymer Science, 6(3), 86-91.

[30]Muzzarelli C, Muzzarelli RAA (2003) Chitin related food science today (and two centurites ago). Agroofood Ind. Hi-Tech 1: 39-42

[31]Cosgrove, J. (2010, Şubat). The Global Chitosan Market. Nutraceuticals World. Erişim adresi:

https://www.nutraceuticalsworld.com/contents/view_o nline-exclusives/2010-12-02/the-global-chitosanmarket-

[32]Muzzarelli RAA (1986) Filmogenic properties of chitin /chitosan. In: Muzzarelli RAR, Jeuniaux, Gooday CW (eds) Chitin in nature and Technology. Pp. 389-396. Plenum Press, NewYork.

[33]Struszczyk H, Orlikowski BL, Skrzypczak C. (2001) Chitosan in the control of soil-borne pathogens. Chitin Enzymology; 197-205. 
[34]El Ghaouth, A., Arul, J., Asselin, A., \& Benhamou, N. (1992). Antifungal activity of chitosan on post-harvest pathogens: induction of morphological and cytological alterations in Rhizopus stolonifer. Mycological research, 96(9), 769-779.

[35]Falcon-Rodriguez AB, Costales D, Cabrera JC, Martinez-Tellez MA (2011) Chitosan physicochemical properties modulate and resistance in tobacco plants against the oomycete Phytophthora nicotianae. Pestic. Biochem. Phys. 100: 221-228.

[36]Feliziani E, Smilanick JL, Morgosan DA, Mansour MF, , Gu S, Gohil HL, Ames ZR (2013) Preharvest fungucide potassium sorbat or chitosan use on quality and storage decay of table grapes. Plant Dis. 97: 307-314.

[37]Romanazzi, G., Gabler, F. M., \& Smilanick, J. L. (2006). Preharvest chitosan and postharvest UV irradiation treatments suppress gray mold of table grapes. Plant Disease, 90(4), 445-450.

[38]Feliziani E, Santini M, Landi L, Romanazzi G (2013) Pre- and Post-harvest treatment with alternatives to synthetic fungucides to control postharvest decay of sweet cherry. Post harvest Biol Tec. 78: 133-138.

[39]Doares SH, Syrovets T, Elmar EW, Weiler W, Ryan CA (1995) Oligogalactronase and chitosan activate plant defensive genes through the octadecanoid pathway. Proc. Nat. Acad. Sci. USA 92: 4095-4098.

[40]Aziz A, Trotel-Aziz P, Dhuicq L, Jeandet P, Couderchet M, Vernet G (2006) Chitosan oligomers and copper sulfate induce grapevine defense reactions and resistance to gray mold and downy mildew. Phytopathology 96: 1188-1194.

[41]Kenra DF, Hadwiger LA (1984) Characterization of the smallest chitosan oligomer that is maximally antifungal to Fusarium solani and elicits pisatin formation in Pisum sativum. Exp. Mycol. 8: 276-281.

[42]Sathiyabana M, Balasubramanian R (1998) Chitosan induces resistance components in Arachis hypogaea against leaf rust caused by Puccinia arachidis. Speg. Crop Prot. 17: 307-313.

[43]Kulikov, S. N., Chirkov, S. N., Il'ina, A. V., Lopatin, S. A., \& Varlamov, V. P. (2006). Effect of the molecular weight of chitosan on its antiviral activity in plants. Applied Biochemistry and Microbiology, 42(2), 200-203.

[44]Vasyukova, N. I., Chalenko, G. I., Gerasimova, N. G., Perekhod, E. A., Ozeretskovskaya, O. L., Il'ina, A. V., ... \& Albulov, A. I. (2000). Chitin and chitosan derivatives as elicitors of potato resistance to late blight. Applied Biochemistry and Microbiology, 36(4), 372-376.

[45]Ren, H., Endo, H., \& Hayashi, T. (2001). Antioxidative and antimutagenic activities and polyphenol content of pesticide-free and organically cultivated green vegetables using water-soluble chitosan as a soil modifier and leaf surface spray. Journal of the Science of Food and Agriculture, 81(15), 1426-1432.
[46]Barber, M. S., Bertram, R. E., \& Ride, J. P. (1989). Chitin oligosaccharides elicit lignification in wounded wheat leaves. Physiological and Molecular Plant Pathology, 34(1), 3-12.

[47]Tikhonov, V. E., Stepnova, E. A., Babak, V. G., Yamskov, I. A., Palma-Guerrero, J., Jansson, H. B., et al. (2006). Bactericidal and antifungal activities of a low molecular weight chitosan and its $\mathrm{N}-/ 2$ (3)-(dodec2-enyl)succinoyl/- derivatives. Carbohydr. Polym. 64, 66-72. doi: 10.1016/j.carbpol.2005.10.021

[48]Rabea, E. I. ve Steurbaut, W. (2010). Chemically modified chitosans as antimicrobial agents against some plant pathogenic bacteria and fungi. Plant Protect. Sci. 46, 149-158.

[49]Trotel-Aziz, P., Couderchet, M., Vernet, G., and Aziz, A. (2006). Chitosan stimulates defense reactions in grapevine leaves and inhibits development of Botrytis cinerea. Eur. J. Plant Pathol. 114, 405-413. doi: 10.1007/s10658-006-0005-5.

[50]Khalil, M. S., and Badawy, M. E. (2012). Nematicidal activity of a biopolymer chitosan at different molecular weights against root-knot nematode, Meloidogyne incognita. Plant Protect Sci. 48, 170-178.

[51]Nunes da Silva, M., Cardoso, A. R., Ferreira, D., Brito, M., Pintado, M. E., and Vasconcelos, M. W. (2014). Chitosan as a biocontrol agent against the pinewood nematode (Bursaphelenchus xylophilus). Plant Pathol. 62, 1398-1406. doi: 10.1111/ppa.12037. [52]Allan, C. R., \& Hadwiger, L. A. (1979). The fungicidal effect of chitosan on fungi of varying cell wall composition. Experimental mycology, 3(3), 285287.

[53]Faoro, F., Sant, S., Iriti, M., Maffi, D., \& Appiano, A. (2001). Chitosan-elicited resistance to plant viruses: a histochemical and cytochemical study. Chitin Enzymology, 22, 57-62.

[54]Chirkov, S. N. (2002). The antiviral activity of chitosan. Applied Biochemistry and Microbiology, 38(1), 1-8.

[55]Pospieszny, H., Chirkov, S., \& Atabekov, J. (1991). Induction of antiviral resistance in plants by chitosan. Plant Science, 79(1), 63-68.

[56]Kong, M., Chen, X. G., Xing, K., \& Park, H. J. (2010). Antimicrobial properties of chitosan and mode of action: a state of the art review. International journal of food microbiology, 144(1), 51-63.

[57]Muzzarelli, R., Tarsi, R., Filippini, O., Giovanetti, E., Biagini, G., \& Varaldo, P. E. (1990). Antimicrobial properties of N-carboxybutyl chitosan. Antimicrobial agents and chemotherapy, 34(10), 2019-2023.

[58]Chung, Y. C., Wang, H. L., Chen, Y. M., \& Li, S. L. (2003). Effect of abiotic factors on the antibacterial activity of chitosan against waterborne pathogens. Bioresource technology, 88(3), 179-184.

[59]Jia, Z., \& Xu, W. (2001). Synthesis and antibacterial activities of quaternary ammonium salt of chitosan. Carbohydrate research, 333(1), 1-6. 
[60]Kim, J. H., Shin, J. H., Lee, H. J., Chung, I. S., \& Lee, H. J. (1997). Effect of chitosan on indirubin production from suspension culture of Polygonum tinctorium. Journal of fermentation and bioengineering, 83(2), 206-208.

[61]Roller, S., \& Covill, N. (1999). The antifungal properties of chitosan in laboratory media and apple juice. International Journal of Food Microbiology, 47(1), 67-77.

[62]Hernandez-Lauzardo, A. N., Bautista-Baños, S., Velazquez-Del Valle, M. G., Méndez-Montealvo, M. G., Sánchez-Rivera, M. M., \& Bello-Perez, L. A. (2008). Antifungal effects of chitosan with different molecular weights on in vitro development of Rhizopus stolonifer (Ehrenb.: Fr.) Vuill. Carbohydrate Polymers, 73(4), 541-547.

[63]Meng, X., Yang, L., Kennedy, J. F., \& Tian, S. (2010). Effects of chitosan and oligochitosan on growth of two fungal pathogens and physiological properties in pear fruit. Carbohydrate Polymers, 81(1), 70-75.

[64]Olicón-Hernández， D. R., Hernández-Lauzardo, A. N., Pardo, J. P., Peña, A., Velázquez-del Valle, M. G., \& Guerra-Sánchez, G. (2015). Influence of chitosan and its derivatives on cell development and physiology of Ustilago maydis. International journal of biological macromolecules, 79, 654-660.

[65]Terrile, M. C., Mansilla, A. Y., Albertengo, L., Rodríguez, M. S., \& Casalongué, C. A. (2015). Nitric-oxide-mediated cell death is triggered by chitosan in Fusarium eumartii spores. Pest management science, 71(5), 668-674.

[66]Hidangmayum, A., Dwivedi, P., Katiyar, D., \& Hemantaranjan, A. (2019). Application of chitosan on plant responses with special reference to abiotic stress. Physiology and molecular biology of plants, 25(2), 313-326.

[67]Ahmad, W., Zahir, A., Nadeem, M., Garros, L., Drouet, S., Renouard, S., ... \& Abbasi, B. H. (2019). Enhanced production of lignans and neolignans in chitosan-treated flax (Linum usitatissimum L.) cell cultures. Process biochemistry, 79, 155-165.

[68]Muley, A. B., Shingote, P. R., Patil, A. P., Dalvi, S. G., \& Suprasanna, P. (2019). Gamma radiation degradation of chitosan for application in growth promotion and induction of stress tolerance in potato (Solanum tuberosum L.). Carbohydrate polymers, 210, 289-301.

[69]Shams Peykani, L. (2018). Effect of chitosan on antioxidant enzyme activity, proline, and malondialdehyde content in Triticum aestivum L. and Zea maize L. under salt stress condition. Plant Physiology, 9(1), 2661-2670.

[70]Khan, A. A. (1992). Preplant physiological seed conditioning. Horticultural reviews, 13(1), 131-181.

[71]Bhaskara Reddy, M. V., Arul, J., Angers, P., \& Couture, L. (1999). Chitosan treatment of wheat seeds induces resistance to Fusarium graminearum and improves seed quality. Journal of Agricultural and Food chemistry, 47(3), 1208-1216.

[72]Zhou, Y. G., Yang, Y. D., Qi, Y. G., Zhang, Z. M., Wang, X. J., \& Hu, X. J. (2002). Effects of chitosan on some physiological activity in germinating seed of peanut. Journal of Peanut Science, 31(1), 2225.

[73]Ruan, S., \& Xue, Q. (2002). Effects of chitosan coating on seed germination and salt-tolerance of seedling in hybrid rice (Oryza sativa L.). Zио wи хие bao, 28(6), 803-808.

[74]Cheah, L. H., \& Page, B. B. C. (1997, August). Trichoderma spp. for potential biocontrol of clubroot of vegetable brassicas. In Proceedings of the New Zealand Plant Protection Conference (pp. 150-153). NEW ZEALAND PLANT PROTECTION SOCIETY INC.

[75]Guan, Y. J., Hu, J., Wang, X. J., \& Shao, C. X. (2009). Seed priming with chitosan improves maize germination and seedling growth in relation to physiological changes under low temperature stress. Journal of Zhejiang University-Science $B, 10(6), 427-433$.

[76]Faoro, F., Maffi, D., Cantu, D., \& Iriti, M. (2008). Chemical-induced resistance against powdery mildew in barley: the effects of chitosan and benzothiadiazole. Biocontrol, 53(2), 387-401.

[77]Iriti, M., Picchi, V., Rossoni, M., Gomarasca, S., Ludwig, N., Gargano, M., \& Faoro, F. (2009). Chitosan antitranspirant activity is due to abscisic acid-dependent stomatal closure. Environmental and Experimental Botany, 66(3), 493-500.

[78]Rabea, E. I., Badawy, M. E. T., Stevens, C. V., Smagghe, G., \& Steurbaut, W. (2003). Chitosan as antimicrobial agent: applications and mode of action. Biomacromolecules, 4(6), 1457-1465.

[79]Murphy, J. G., Rafferty, S. M., \& Cassells, A. C. (2000). Stimulation of wild strawberry (Fragaria vesca) arbuscular mycorrhizas by addition of shellfish waste to the growth substrate: interaction between mycorrhization, substrate amendment and susceptibility to red core (Phytophthora fragariae). Applied Soil Ecology, 15(2), 153-158.

[80]Chookhongkha, N., Miyagawa, S., Jirakiattikul, Y., \& Photchanachai, S. (2012, November). Chili growth and seed productivity as affected by chitosan. In Proceedings of the International Conference on Agriculture Technology and Food Sciences (ICATFS'2012), Manila, Philippines (pp. 17-18).

[81]Kuchitsu, K., Yazaki, Y., Sakano, K., \& Shibuya, N. (1997). Transient cytoplasmic pH change and ion fluxes through the plasma memberan in suspensioncultured rice cells triggered by Nacetylchitooligosaccharide elicitor. Plant and cell physiology, 38(9), 1012-1018.

[82]Kuchitsu, K., Kosaka, H., Shiga, T., \& Shibuya, N. (1995). EPR evidence for generation of hydroxyl radical triggered byN-acetylchitooligosaccharide 
elicitor and a protein phosphatase inhibitor in suspension-cultured rice cells. Protoplasma, 188(1-2), 138-142.

[83]Nojiri, H., Sugimori, M., Yamane, H., Nishimura, Y., Yamada, A., Shibuya, N., ... \& Omori, T. (1996). Involvement of jasmonic acid in elicitor-induced phytoalexin production in suspension-cultured rice cells. Plant Physiology, 110(2), 387-392.

[84]Takai, R., Hasegawa, K., Kaku, H., Shibuya, N., \& Minami, E. (2001). Isolation and analysis of expression mechanisms of a rice gene, EL5, which shows structural similarity to ATL family from Arabidopsis, in response to $\mathrm{N}$ acetylchitooligosaccharide

Science, 160(4), 577-583.

[85]Bornet, A., \& Teissedre, P. L. (2008). Chitosan, chitin-glucan and chitin effects on minerals (iron, lead, cadmium) and organic (ochratoxin A) contaminants in wines. European Food Research and Technology, 226(4), 681-689.

[86]N. Ben-Shalom, in R. Brzezinski, I. Boucher, A. Retnakaran (Eds.), Chitosan-metal complex as a natural agricultural product against plant diseases, in: Proceedings of the 9th International Chitin-Chitosan Conference, Montréal, Canada, August 27-30, 2003.

[87]Varma, A. J., Deshpande, S. V., \& Kennedy, J. F. (2004). Metal complexation by chitosan and its derivatives: a review. Carbohydrate Polymers, 55(1), 77-93.

[88]Muzzarelli, R. (1992). Depolymerization of methyl pyrrolidinone chitosan by lysozyme. Carbohydrate polymers, 19(1), 29-34.

[89]Vasconcelos, M., Datta, K., Oliva, N., Khalekuzzaman, M., Torrizo, L., Krishnan, S., et al. (2003). Enhanced iron and zinc accumulation in transgenic rice with the ferritin gene. Plant Sci. 164, 371-378. doi: 10.1016/S0168-9452(02)00421-1

[90]Chung, Y. C., Kuo, C. L., \& Chen, C. C. (2005). Preparation and important functional properties of water-soluble chitosan produced through Maillard reaction. Bioresource Technology, 96(13), 1473-1482. [91]Bostan, K., Aldemir, T., \& Aydın, A. (2007). Kitosan ve antimikrobiyal aktivitesi. Türk Mikrobiyal Cem Dergisi, 37(2), 118-127.

[92]Kurt, Ş., \& Zorba, Ö. (2005). Kitin (Chitin), Kitosan (Chitosan) ve Türevlerinin Gidalarda Kullanım Olanakları. GIDA/THE JOURNAL OF FOOD, 30(6).

[93]Hadwiger, L. A., Kendra, D. F., Fristensky, B. W., \& Wagoner, W. (1986). Chitosan both activates genes in plants and inhibits RNA synthesis in fungi. In Chitin in nature and technology (pp. 209-214). Springer, Boston, MA.

[94]Limpanavech, P., Chaiyasuta, S., Vongpromek, R., Pichyangkura, R., Khunwasi, C., Chadchawan, S., ... \& Bangyeekhun, T. (2008). Chitosan effects on floral production, gene expression, and anatomical changes in the Dendrobium orchid. Scientia Horticulturae, 116(1), 65-72.
[95]Hadwiger, L. A. (2013). Multiple effects of chitosan on plant systems: solid science or hype. Plant science, 208, 42-49.

[96]Cho, M. H., No, H. K., \& Prinyawiwatkul, W. (2008). Chitosan treatments affect growth and selected quality of sunflower sprouts. Journal of food science, 73(1), S70-S77.

[97]Singh, S. (2016). Enhancing phytochemical levels, enzymatic and antioxidant activity of spinach leaves by chitosan treatment and an insight into the metabolic pathway using DART-MS technique. Food chemistry, 199, 176-184.

[98]Levine, A., Tenhaken, R., Dixon, R., \& Lamb, C. (1994). H2O2 from the oxidative burst orchestrates the plant hypersensitive disease resistance response. Cell, 79(4), 583-593.

[99]Loake, G., \& Grant, M. (2007). Salicylic acid in plant defence- the players and protagonists. Current opinion in plant biology, 10(5), 466-472.

[100]Janda, M., \& Ruelland, E. (2015). Magical mystery tour: salicylic acid signalling. Environmental and Experimental Botany, 114, 117-128.

[101]Koornneef, A., \& Pieterse, C. M. (2008). Cross talk in defense signaling. Plant physiology, 146(3), 839-844.

[102]Zhang, S., Li, X., Sun, Z., Shao, S., Hu, L., Ye, M., ... \& Shi, K. (2015). Antagonism between phytohormone signalling underlies the variation in disease susceptibility of tomato plants under elevated CO2. Journal of Experimental Botany, 66(7), 19511963.

[103]Rakwal, R., Tamogami, S., Agrawal, G. K., \& Iwahashi, H. (2002). Octadecanoid signaling component "burst" in rice (Oryza sativa L.) seedling leaves upon wounding by cut and treatment with fungal elicitor chitosan. Biochemical and Biophysical Research Communications, 295(5), 1041-1045.

[104]Yin, H., Li, Y., Zhang, H. Y., Wang, W. X., Lu, H., Grevsen, K., ... \& Du, Y. (2013). Chitosan oligosaccharides-triggered innate immunity contributes to oilseed rape resistance against Sclerotinia Sclerotiorum. International Journal of Plant Sciences, 174(4), 722-732.

[105]Jia, X., Meng, Q., Zeng, H., Wang, W., \& Yin, H. (2016). Chitosan oligosaccharide induces resistance to Tobacco mosaic virus in Arabidopsis via the salicylic acid-mediated signalling pathway. Scientific reports, 6, 26144.

[106]Zhang, H., Zhao, X., Yang, J., Yin, H., Wang, W., Lu, H., \& Du, Y. (2011). Nitric oxide production and its functional link with OIPK in tobacco defense response elicited by chitooligosaccharide. Plant cell reports, 30(6), 1153-1162.

[107]Malerba, M., Crosti, P., \& Cerana, R. (2012). Defense/stress responses activated by chitosan in sycamore cultured cells. Protoplasma, 249(1), 89-98.

[108]Iriti, M., \& Varoni, E. M. (2015). Chitosaninduced antiviral activity and innate immunity in plants. Environmental Science and Pollution Research, 22(4), 2935-2944. 
[109]Ghasemnezhad, M., \& Shiri, M. A. (2010). Effect of chitosan coatings on some quality indices of apricot (Prunus armeniaca L.) during cold storage. Caspian Journal of Environmental Sciences, 8(1), 25-33.

[110]Ali, A., Muhammad, M. T. M., Sijam, K., \& Siddiqui, Y. (2011). Effect of chitosan coatings on the physicochemical characteristics of Eksotika II papaya (Carica papaya L.) fruit during cold storage. Food chemistry, 124(2), 620-626.

[111]FAO Statistical Yearbook 2013. (2014, 16 Eylül).

Erişim adresi:

http://www.fao.org/docrep/018/i3107e/i3107e00.htm) 